\title{
Metabolismo nitrogenado em bovinos suplementados a pasto durante a transição águas seca
}

\author{
Goes, R.H.T.B. ${ }^{1}$; Gandra, J.R. ${ }^{1}$; Marquez, A.F. ${ }^{1}$; Oliveira, E.R. de ${ }^{1}$; Fernandes, H.J. ${ }^{2}$; Cardoso, T.J. de L. ${ }^{\text {; }}$ Brabes, K.C. da \\ S. ${ }^{1}$ e Yoshihara, M.M.'
}

\begin{abstract}
'Universidade Federal da Grande Dourados. Faculdade de Ciências Agrárias. Dourados. Mato Grosso do Sul. Brasil.
\end{abstract}
${ }^{2}$ Universidade Estadual do Mato Grosso do Sul. Departamento de Zootecnia. Aquidauana. Mato Grosso do Sul. Brasil.

\section{PalaVRas chaVe adicionaIS}

Metabolismo nitrogenado.

Sal proteinado.

Fermentação ruminal.

Proteína microbiana.

\section{RESUMO}

Objetivou-se com este estudo avaliar o consumo, a fermentação ruminal, síntese de proteina microbiana, balanço dos compostos nitrogenados e comportamento ingestivo de suplemento de novilhos mantidos a pasto, suplementados com níveis crescentes de proteína bruta. Foram utilizados 4 novilhos mestiços, com idade média de 24 meses, peso corporal médio de $400 \mathrm{~kg}$, providos de cânula ruminal. Os animais foram mantidos em piquetes individuais, em delineamento quadrado latino $4 \times 4$. Os suplementos experimentais foram constituídos por diferentes níveis de proteína: T00 = Suplemento mineral (controle); $\mathrm{T} 20=\mathrm{Su}$ plemento concentrado com $20 \%$ de PB; T40= Suplemento concentrado com $40 \%$ de PB; T60 = Suplemento concentrado com $60 \%$ de PB. Não foi observado efeito sobre o consumo de matéria seca. Foi observado efeito sobre as concentrações de valerato, porém não foram observadas respostas lineares ou quadráticas. $\mathrm{O}$ tratamento T60 apresentou menor velocidade de ingestão de suplemento em relação aos demais. Os níveis de suplementação proteica não influenciaram o consumo de matéria seca, síntese de proteína microbiana e balanço de compostos nitrogenados, porem influenciaram as concentrações de ácidos graxos de cadeia ramificada e a velocidade de consumo de suplemento proteico.

Nitrogen metabolism in steers under grazing during the rainy/dry transition period SUMMARY

\author{
ADDITIONAL KEYWORDS \\ Nitrogen metabolism. \\ Protein salt. \\ Ruminal fermentation. \\ Microbial protein.
}

\section{INFORMACIÓN}

Cronología del artículo.

Recibido/Received: 22.1.2015

Aceptado/Accepted: 10.8.2015

On-line: 16.9.2015

Correspondencia a los autores/Contact e-mail:

rafaelgoes@ufgd.edu.br

\section{INTRODUÇÃO}

A sazonalidade na produção das forrageiras tropicais, visando o crescimento contínuo de bovinos mantidos em pasto deve ser delineada dentre as práticas de manejo que têm sido adotadas para minimizar as perdas ocorridas durante o período de escassez de forragem, o diferimento da pastagem destaca-se pela praticidade e baixo custo. Entretanto, pastagens diferidas geralmente apresentam boa oferta, mas baixo valor nutritivo da forragem ofertada (Euclides et al., 2007). Dessa maneira, para que se obtenha bom desempenho animal, a utilização de pastagens diferidas deve estar associada à suplementação alimentar o que irá permitir a manutenção da curva de crescimento dos bovinos (Silva et al., 2009).

Uma estratégia de suplementação adequada seria aquela destinada a maximizar o consumo e a digestibilidade da forragem disponível. Sendo assim, a 
condição básica para se promover a suplementação é que haja boa disponibilidade de massa forrageira na pastagem, mesmo sendo de baixa qualidade. O desafio é predizer, com eficiência, o impacto que a suplementação causará no desempenho animal (Silva et al., 2009). Para tanto, torna-se fundamental caracterizar a quantidade e a qualidade da forragem ofertada, bem como avaliar o consumo de forragem pelos animais. Portanto, a utilização de suplementos concentrados pode auxiliar no manejo das pastagens, otimizar o desempenho de animais a pasto e acelerar o sistema de produção de carne, encurtando a idade de abate e atendendo às exigências de mercado por carne de melhor qualidade (Poppi and McLennan, 1995).

O consumo está relacionado à redução de digestibilidade, ao $\mathrm{pH}$ ruminal e às respostas ao nível de suplemento oferecido. A presença de carboidratos não estruturais provoca queda no pH e redução no crescimento de bactérias celulolíticas, o que diminui o consumo e degradabilidade de suplementados em níveis elevados (Detmann et al., 2005). Os níveis de amônia são alterados por captação pelos microrganismos e absorção pela parede do rúmen e omaso (Owens and Zinn, 1993). As concentrações de amônia no rúmen podem variar de acordo com a solubilidade da fonte de nitrogênio, alcançando valores máximos de 1 a 2 horas após alimentação (Detmann et al., 2007). A concentração de amônia no rúmen pode ser criticamente baixa quando a dieta é muito pobre em proteína bruta (Goes et al., 2010).

Depois da energia a proteína é o nutriente mais requerido pelos ruminantes, ocorrendo redução no consumo quando os níveis atingem menos de $7 \%$ de PB na MS (Lima et al., 2012), por não atender as exigências mínimas dos microorganismos do rúmen. A deficiência de nitrogênio limita o crescimento microbiano, reduz a digestibilidade da parede celular, o consumo e o desempenho animal, e o excesso de proteína promove excreção de uréia via urina (Sales et al., 2008).

O comportamento ingestivo dos ruminantes está diretamente ligado ao próprio animal, ao meio ambiente, às plantas, ao manejo adotado, e ao fornecimento ou não de suplementação. O comportamento ingestivo de suplementos protéicos não é bem discutido na literatura. $\mathrm{O}$ embasamento científico sobre o comportamento ingestivo, no entanto, pode melhorar o manejo dos animais. Sabendo-se que a produção de bovinos a pasto está diretamente relacionada ao tempo de pastejo da forragem, fica clara a necessidade do estudo desta característica.

Desta forma o objetivo deste estudo é avaliar a fermentação ruminal, balanço dos compostos nitrogenados e comportamento ingestivo de novilhos mantidos a pasto, suplementados com níveis crescentes de proteína bruta.

\section{MATERIAL E MÉTODOS}

\section{ANIMAIS E DIETAS}

O experimento foi conduzido no setor de Zootecnia da Universidade Federal da Grande Dourados (UFGD), localizada nas coordenadas $22^{\circ} 11^{\prime} 43,49^{\prime \prime} \mathrm{de}$
Tabela I. Composição dos suplementos proteicos experimentais (Composition of experimental protein supplements).

\begin{tabular}{lccrr}
\hline & \multicolumn{4}{c}{ Suplementos $^{1}$} \\
\cline { 2 - 5 } Ingredientes (\%) & 00 & 20 & 40 & \multicolumn{1}{c}{60} \\
\hline Fubá de milho & - & 30,00 & 6,00 & 5,00 \\
Farelo de arroz & - & 14,90 & 20,00 & 5,00 \\
Farelo de trigo & - & 8,00 & 5,70 & 10,00 \\
Farelo de soja & - & - & 14,00 & 18,00 \\
Casca de soja & - & 18,00 & 17,50 & 20,00 \\
Sal comum & - & 13,00 & 14,80 & 15,00 \\
Uréia pecuária & - & 4,60 & 10,00 & 15,00 \\
Carbonato de cálcio & - & - & 1,00 & 1,00 \\
Fosfato bicálcico & - & 9,50 & 9,00 & 9,00 \\
Flor de enxofre & - & 1,00 & 1,00 & 1,00 \\
Mistura mineral ${ }^{2}$ & 100 & 1,00 & 1,00 & 1,00 \\
\hline Nutrientes(\%) & & & & \\
\hline MS & & & & \\
MM & 99,87 & 88,98 & 87,56 & 86,76 \\
EE & 99,90 & 29,06 & 37,43 & 36,24 \\
FDN & - & 3,88 & 3,80 & 2,02 \\
FDA & - & 21,25 & 21,90 & 19,21 \\
\hline
\end{tabular}

${ }^{1}$ Suplemento 00 (sal mineralizado); Suplemento 20 (suplemento proteico com $20 \%$ de PB); Suplemento 40 (suplemento proteico com $20 \%$ de PB); Suplemento 60 (suplemento proteico com $60 \%$ de PB). ${ }^{2}$ Níveis de garantia (kg/produto): Cálcio: 120,00 g; Fósforo: 88,00 g; lodo: $75,00 \mathrm{mg}$; Manganês: $1300,00 \mathrm{mg}$; Sódio: $126,00 \mathrm{~g}$; Selênio: 15,00 mg; Enxofre: 12,00 mg; Zinco: 3630,00 mg; Cobalto: $55,50 \mathrm{mg}$; Cobre: $1530,00 \mathrm{mg}$ e Ferro: $1800,00 \mathrm{mg}$.

latitude sul e 54 $55^{\prime} 77^{\prime \prime}$ de longitude oeste, entre os meses de março a maio de 2010.

Foram utilizados quatro novilhos mestiços, castrados, com idade média de 24 meses, peso corporal médio de $400 \mathrm{~kg}$, providos de cânula ruminal. Os animais foram mantidos em piquetes individuais, em delineamento quadrado latino $4 \times 4$ e rotacionados a cada 14 dias a fim de se reduzir o efeito da forragem. O período experimental total de 84 dias, sendo cada período experimental de 21 dias.

Os piquetes eram formados pela forrageira Brachiária brizantha 'Marandu', com área de 0,3 ha, divididos por cerca elétrica de dois fios, com bebedouro e cocho. O curral para manejo dos animais se localizava próximo dos piquetes, e os animais eram conduzidos através de corredores. O consumo de suplemento foi controlado e ajustado de acordo com a quantidade consumida a cada três dias. Os tratamentos foram constituídos por diferentes níveis de proteína: T00= Suplemento mineral (controle); T20= Suplemento concentrado com $20 \%$ de PB; T40= Suplemento concentrado com $40 \%$ de PB; T60= Suplemento concentrado com $60 \%$ de PB (tabela I).

\section{DISPONIBILIDADE DE FORRAGEM}

No primeiro dia de cada período experimental, foi determinada a disponibilidade total de forragem, através do corte rente ao solo de 10 áreas delimitadas por quadrados metálicos $\left(0,25 \mathrm{~m}^{2}\right)$ aleatoriamente dentro 
de cada piquete, conforme descrito por McMeniman (1997). Posteriormente, as amostras foram uniformizadas por piquete onde se retiraram duas amostras, uma para a determinação da composição bromatológica.

A coleta da forrageira ingerida pelos animais (extrusa) ocorreu no $14^{\circ}$ dia experimental de cada período, através do esvaziamento ruminal (McMenimann, 1997). Anteriormente a coleta os animais foram submetidos a jejum por 12 horas, para se garantir o consumo total da forragem e evitar contaminação do material já presente no rúmen (McMenimann, 1997). A coleta de extrusa foi realizada ás 08 h 00 min; o rúmen foi esvaziado e seco com panos de algodão e limpo. Após o esvaziamento ruminal os animais foram recolocados em seus respectivos piquetes e pastejaram por aproximadamente 30 minutos, e recolhidos ao curral onde foi retirado o material ingerido presente no rúmen. Coletou-se em média de $400 \mathrm{~g}$ de extrusa, que foi armazenada em sacos plásticos, identificada, e transportada dentro de uma caixa de isopor.

\section{ANÁLISES BROMATOLÓGICAS}

As amostras de forragem e de suplemento foram analisadas quanto aos teores de matéria seca (MS), proteína bruta (PB), extrato etéreo (EE), Cinzas (CZ), conforme técnicas descritas por AOAC (2002) e fibra em detergente neutro (FDN) e ácido (FDA), lignina (LIG), foram realizadas de acordo com (Van Soest et al., 1991) A digestibilidade in vitro da matéria seca (DIVMS), foi determinada de acordo com metodologia descrita por Tilley and Terry (1963), com uso do incubador in vitro, da Tecnal ${ }^{\circledR}$ (TE-150), com modificação do material do saquinho utilizado (confeccionado com TNT - $100 \mathrm{~g} /$ $\mathrm{m} 2$ ), conforme sugerido por Casali et al. (2008). Os teores de nutrientes digestíveis totais (NDT) da pastagem foram estimados segundo equação propostas por (Capelle et al., 2001). O teor de NDT da forragem foi calculado baseado no teor de FDA, conforme equação:

$$
\% \mathrm{NDT}=74,49-0,5635^{*} \mathrm{FDA}\left(\mathrm{R}^{2}=0,82\right) .
$$

\section{CONSUMO DE MATÉRIA SECA}

As sobras dos suplementos foram pesadas diariamente, ajustando o fornecimento para um consumo ad libitum, sendo calculada a média de consumo a cada três dias e fornecendo o suplemento de acordo com a média calculada.

O óxido de cromo foi inserido diretamente por cânula ruminal do $9^{\circ}$ ao $19^{\circ}$ dia de cada período experimental na dose de 10g/dia $1 \mathrm{vez}$ ao dia. O óxido de cromo foi pesado em balança analítica e colocado em um envelope de papel de celulose, totalmente degradável.

As amostras fecais foram coletadas diretamente na ampola retal dos animais, nos tempos $0,4,8,12,16,22$, $28,34,40,52,64,76$ e 100 horas após o fornecimento do indicador, segundo recomendações de Detmann et al. (2001). As análises do teor de cromo nas fezes foram realizadas por espectrofotometria de absorção atômica em forno de grafite, conforme metodologia descrita por (Williams et al., 1962).

Para a determinação da produção de matéria seca fecal foi utilizada a fórmula: $\mathrm{g}$ MS fecal excretada por dia $=\left(100 \times \mathrm{Cr}_{2} \mathrm{O}_{3}\right.$ fornecido $) /\left(\%\right.$ de $\mathrm{Cr}_{2} \mathrm{O}_{3}$ na MS fecal $)$. A FDA indigestível foi utilizada para a estimativa de consumo de forragem, determinada segundo Detmann et al. (2001) com base na degradabilidade in situ, por 144 horas.

O consumo de matéria seca foi determinado empregando-se a equação:

$$
\mathrm{CMS}=\{[(\mathrm{EF} \times \mathrm{CIFZ})-\mathrm{IS}] / \mathrm{CIFO}\}+\mathrm{CMSS} ;
$$

Onde:

$$
\mathrm{CMS}=\text { consumo de matéria seca }(\mathrm{kg} / \mathrm{dia}) \text {; }
$$$$
\mathrm{EF}=\text { excreção fecal (kg/dia); }
$$

$\mathrm{CIFZ}=$ concentração do indicador presente nas fezes $(\mathrm{kg} / \mathrm{kg})$;

IS= indicador presente no suplemento $(\mathrm{kg} / \mathrm{dia})$;

$\mathrm{CIFO}=$ concentração do indicador presente na forragem $(\mathrm{kg} / \mathrm{kg})$,

$\mathrm{CMSS}=$ consumo de matéria seca do suplemento (kg/dia).

\section{PARÂMETROS RUMINAIS}

No $21^{\circ}$ dia experimental foram coletadas amostras de líquido ruminal, as $08 \mathrm{~h} 00 \mathrm{~min}(0 \mathrm{~h})$. As coletas de liquido ruminal, para a determinação de $\mathrm{pH}$, nitrogênio amoniacal e ácidos graxos de cadeia curta (AGCC) foram realizadas na interface líquido/sólido do ambiente ruminal, filtradas por uma camada tripla de gaze, antes do fornecimento do concentrado (0h) e 2, 4, 6 e 8 horas após o fornecimento. A determinação do $\mathrm{pH}$ foi realizada em $40 \mathrm{ml}$ de liquido ruminal de cada animal em cada tempo, imediatamente após a coleta e aferido com peagâmetro digital. Para a determinação do nitrogênio amoniacal foi utilizado metodologia de acordo com (Campos et al., 2004). Para determinação dos AGCC foi utilizado metodologia de acordo com (Erwin et al., 1961).

\section{SíNTESE DE PROTEÍNA MICROBIANA E BALANÇO DE COMPOSTOS NITROGENADOS}

A coleta de urina foi realizada no $20^{\circ}$ dia, na forma spot, quatro horas após o fornecimento do suplemento via massegem prepucial ou por micção espontânea dos animais, destinada à determinação da concentração de creatinina urinária, uréia, ácido úrico e alantoína, segundo (Valadares et al., 1999).

As análises de alantoína foram realizadas pelo método colorimétrico, conforme técnica de Fujihara et al. (1987), descrita por Chen and Gomes (1992). A excreção total de derivados de purina (DP) foi calculada pela soma das quantidades de alantoína e ácido úrico excretadas na urina, expressas em $\mathrm{mmol} / \mathrm{dia}$. As purinas microbianas absorvidas (Pabs, mmol/dia) foram calculadas a partir da excreção de derivados de purinas na urina (DP, mmol/dia), por meio da equação:

$$
\mathrm{DP}=0,85^{*} \mathrm{Pabs}+0,385^{*} \mathrm{PV}^{0,75} \text {, }
$$

em que 0,85 é a recuperação de purinas absorvidas como derivados urinários de purinas e 0,385 PV $\mathrm{PV}^{0,75}$, a contribuição endógena para a excreção de purinas (Verbic et al., 1990). 
As excreções diárias de N-uréia e N-creatinina foram obtidas por meio do produto das concentrações de uréia e creatinina pelo volume urinário de 24 horas, multiplicado por 0,466 ou 0,3715 ; correspondente aos teores de $\mathrm{N}$ na uréia e creatinina, respectivamente (Rennó et al., 2000).

O volume urinário foi calculado da seguinte maneira:

$\mathrm{VU}(1 /$ dia $)=(27,36 \times \mathrm{PV}) /[$ creatinina $]$,

Onde 27,36 representam o valor da excreção diária média de creatinina, em ppm PV, obtido por Rennó et al. (2000) em novilhos cruzados e zebuínos, PV é o peso vivo do animal e [creatinina] é a concentração de creatinina, em $\mathrm{mg} / \mathrm{L}$, encontrada na amostra de urina spot dos animais.

No dia 9, 10, 11, 12 e 13 de cada período experimental, as $07 \mathrm{~h} 00 \mathrm{~min}$, foram realizadas coletas de sangue, totalizando cinco amostragens, para posterior análise dos níveis de uréia plasmática. Para o calculo do balanço de nitrogênio foi analisado o conteúdo de nitrogênio da urina, fezes e alimentos através do método de Kjeldahl de acordo com (AOAC, 2002), sendo este calculado a partir da diferença entre o consumo de nitrogênio (g/dia) e a excreção de nitrogênio (g/dia) nas fezes e na urina.

\section{COMPORTAMENTO INGESTIVO DE SUPLEMENTO}

O comportamento ingestivo dos suplementos concentrados foi determinado no $15^{\circ}$ dia por meio do peso das sobras de suplemento nos cochos aos 20, 40, 60, 90, 120, 180, 300, 420, 540 e 1440 minutos após o fornecimento do concentrado (Brody, 1945).

\section{ANÁLISES ESTATÍSTICAS}

Os dados obtidos foram submetidos ao SAS (Version 9.1.3, SAS Institute, Cary, NC, 2004), verificando a normalidade dos resíduos e a homogeneidade das variâncias pelo PROC UNIVARIATE.

Os dados foram analisados, pelo PROC MIXED de acordo com a seguinte modelo:

$$
Y_{i j k=} \mu+A_{i}+P_{j}+D_{k}+e_{i j k}
$$

Onde:

$$
\begin{aligned}
& Y_{i j y k}=\text { variável dependente, } \\
& \mu=\text { media geral, } \\
& A_{i}=\text { efeito de animal }(j=1 \text { a } 4), \\
& P j=\text { efeito do período }(y=1 \text { a } 4), \\
& \left.D_{k}=\text { efeito da dieta ( } k=1 \text { to } 4\right) \text {, e } \\
& e_{i j k}=\text { erro. }
\end{aligned}
$$

Para os dados obtidos pela fermentação ruminal foram analisados pelo PROC MIXED de acordo com a seguinte modelo:

$$
Y_{i j k}=\mu+A_{i}+P_{j}+D_{k}+T_{y}+T_{y}\left(D_{k}\right) e_{i j k}
$$

Onde:

$$
\begin{aligned}
& Y_{i j y k}=\text { variável dependente, } \\
& \mu=\text { media geral, }
\end{aligned}
$$

$$
\begin{aligned}
& A_{i}=\text { efeito de animal }(j=1 \text { a } 4), \\
& P j=\text { efeito do período }(y=1 \text { a } 4), \\
& D_{k}=\text { efeito do tratamento }(k=1 \text { to } 4), \\
& \left.T_{y}=\text { efeito do tempo (1 a } 5\right), \\
& T_{y}\left(D_{k}\right)=\text { interação entre dieta e tempo e } \\
& e_{i j k}=\text { erro. }
\end{aligned}
$$

Os dados obtidos foram submetidos à análise de variância e regressão polinomial pelo comando PROC MIXED do SAS, versão 9.0 (SAS, 2009), adotando-se nível de significância de $5 \%$. Para o comportamento ingestivo o consumo de suplemento concentrado para cada tratamento, ajustou-se um modelo proposto por Brody do tipo:

$$
\mathrm{Y}=\mathrm{a}^{*}\left(1-\mathrm{e}^{\left(-\mathrm{k}^{*} \mathrm{X}\right)}\right)
$$

Onde $a$ e $k$ são os parâmetros do modelo, e é o algarismo neperiano, e Y e $\times$ as variáveis.

Este modelo foi ajustado de forma que descrevesse o padrão de consumo do suplemento concentrado (Y) em função do tempo $(X)$, durante 24 horas, referente aquele tratamento. Os padrões de ingestão dos tratamentos foram comparados através do intervalo de $95 \%$ de confiança dos parâmetros estimados do modelo Brody (Kaps and Lamberson, 2004).

\section{RESULADOS E DISCUSSÃO}

\section{DISPONIBILIDADE DE FORRAGEM}

A quantidade total de matéria verde (MV) disponível observada durante o experimento foi de $6.813,50 \mathrm{~kg} / \mathrm{ha}$ e $2.781,40 \mathrm{~kg}$ MS/ha. De acordo com Silva et al. (2009), a produção adequada de forragem está entre $4.500 \mathrm{~kg} \mathrm{MV} /$ ha e $1.200 \mathrm{~kg}$ MS/ha para que haja seletividade do animal. Ferreira et al. (2012) mensuraram a disponibilidade da Brachiária brizantha 'Marandu' em búfalos sob pastejo, observando uma média anual de $6.250 \mathrm{~kg}$ de MV/ha e $2.360 \mathrm{~kg}$ de MS/ ha, resultados semelhantes ao presente estudo. A composição bromatológica da pastagem neste período foi de: MS 33,04\%; PB 5,04\%; FDN 70,94\%; FDA 36,01\%; LIG 5,90\%; NDT 50,56\%; DIVMS 62,02\% resultados semelhantes observados por (Ferreira et al., 2012).

\section{COMPOSIÇ̃̃O BROMATOLÓGICA DA EXTRUSA}

Em relação à composição das extrusas em função dos suplementos experimentais não foi observado ( $p>0,05)$ efeito da suplementação proteica e resposta linear ou quadrática (tabela II). A extrusa obtida através do esvaziamento total do rúmen permite obter amostras semelhantes à extrusa esofágica, desta forma a simulação do pastejo, mais representativa de acordo com a seletividade dos bovinos em pastejo. Lima et al. (2012) avaliaram a estrusa de bovinos pastejando Brachiária brizantha 'Marandu', e observaram resultados semelhantes a média apresentada neste estudo.

O valor médio observado, em termos de PB para a extrusa, foi de $9,77 \%$ (tabela II) que foi superior aos limites de 6,0 e 8,0\% considerado como nível crítico, 
Tabela II. Composição bromatológica das extrusas de acordo com os suplementos proteicos experimentais (Bromatological composition of extrusa according to the experimental protein supplements).

\begin{tabular}{|c|c|c|c|c|c|c|c|c|}
\hline \multirow[t]{2}{*}{ Item } & \multicolumn{4}{|c|}{${ }^{1}$ Suplementos } & \multirow{2}{*}{$\begin{array}{l}\text { CV } \\
(\%)\end{array}$} & \multicolumn{3}{|c|}{${ }^{2}$ Valor de $p$} \\
\hline & 00 & 20 & 40 & 60 & & Suplemento & Linear & Quadrático \\
\hline MS & 15,75 & 14,80 & 14,22 & 13,78 & 5,82 & 0,340 & 0,413 & 0,430 \\
\hline PB & 9,81 & 8,65 & 9,78 & 10,87 & 9,27 & 0,334 & 0,514 & 0,741 \\
\hline FDN & 75,30 & 70,40 & 74,82 & 72,32 & 3,12 & 0,769 & 0,513 & 0,614 \\
\hline FDA & 37,89 & 27,89 & 33,00 & 35,08 & 12,62 & 0,876 & 0,896 & 0,541 \\
\hline LIG & 6,21 & 5,52 & 6,36 & 5,26 & 9,10 & 0,564 & 0,139 & 0,651 \\
\hline NDT & 53,95 & 54,68 & 56,22 & 52,55 & 2,81 & 0,874 & 0,543 & 0,543 \\
\hline DIVMS & 67,25 & 70,28 & 67,95 & 66,40 & 2,45 & 0,132 & 0,412 & 0,578 \\
\hline $\mathrm{CZ}$ & 10,43 & 10,36 & 9,67 & 10,06 & 3,42 & 0,513 & 0,651 & 0,423 \\
\hline NDT:PB & 5,49 & 6,32 & 5,75 & 4,83 & 11,04 & 0,549 & 0,513 & 0,520 \\
\hline
\end{tabular}

1Suplemento 00 (sal mineralizado); Suplemento 20 (suplemento proteico com $20 \%$ de PB); Suplemento 40 (suplemento proteico com $20 \%$ de PB); Suplemento 60 (suplemento proteico com $60 \%$ de PB). ${ }^{2}$ Probabilidade de efeito de dieta, linear e quadrático.

Tabela III. Consumo de matéria seca total, forragem e suplemento de acordo com os suplementos proteicos experimentais (Total dry matter, forage and supplement intake according to the experimental protein supplements).

\begin{tabular}{|c|c|c|c|c|c|c|c|c|}
\hline \multirow[t]{2}{*}{ Item } & \multicolumn{4}{|c|}{${ }^{1}$ Suplementos } & \multirow{2}{*}{$\begin{array}{l}\text { CV } \\
(\%)\end{array}$} & \multicolumn{3}{|c|}{${ }^{2}$ Valor de $p$} \\
\hline & 00 & 20 & 40 & 60 & & Suplemento & Linear & Quadrático \\
\hline \multicolumn{9}{|c|}{ Consumo MS (kg/dia) } \\
\hline Forragem & 5,31 & 3,76 & 4,63 & 4,59 & 19,56 & 0,123 & 0,675 & 0,342 \\
\hline Suplemento & 0,126 & 0,765 & 0,759 & 0,615 & 10,67 & 0,645 & 0,453 & 0,234 \\
\hline Total & 5,43 & 4,52 & 5,38 & 5,20 & 9,78 & 0,657 & 0,432 & 0,554 \\
\hline
\end{tabular}

${ }^{1}$ Suplemento 00 (sal mineralizado); Suplemento 20 (suplemento proteico com $20 \%$ de PB); Suplemento 40 (suplemento proteico com $20 \%$ de PB); Suplemento 60 (suplemento proteico com $60 \%$ de PB). ${ }^{2}$ Probabilidade de efeito de dieta, linear e quadrático.

abaixo do qual comprometeria o funcionamento do ambiente ruminal (Poppi and McLennan, 1995).

\section{CONSUMO DE MATÉRIA SECA}

Em relação ao consumo de matéria seca não foi observado efeito $(p>0,05)$ da suplementação proteica para o consumo de suplemento, e também não foi observado $(p>0,05)$ resposta linear ou quadrática (tabela III). Não foi observado efeito para o consumo de forragem e consumo de matéria seca total. A ausência de alteração sobre o consumo total e de forragem com a modificação dos níveis protéicos dos suplementos não corresponde a relatos sob condições de forragem de baixa qualidade, onde se observam médias elevações no consumo de forragem em função de maiores níveis de PB Detmann et al. (2005), este dado confirma que a disponibilidade de forragem foi adequada para bovinos em pastejo no período experimental.

\section{PARÂMETROS RUMINAIS}

Os valores de $\mathrm{pH}$ ruminal foram influenciados $(p<0,05)$ pelas dietas experimentais, onde ocorreu uma redução significativa, porém não foi observado resposta linear ou quadrática $(p>0,05)$ (tabela IV). De acordo Detmann et al. (2007), o limite mínimo para que ocorra uma inibição da digestão da fibra, do crescimento microbiano e da fermentação ruminal seria de 6,5. Todos os valores de $\mathrm{pH}$ encontrados estão acima deste limite. Valores inferiores a estes acarretam redução significativa do processo de degradação do alimento e valores inferiores a 6,0 praticamente não ocorre degradação da fibra (Sales et al., 2008).

Em relação ao $\mathrm{N}$-amoniacal foi observado efeito da suplementação proteica $(p<0,05)$, no entanto não foi observado resposta linear ou quadrática $(p>0,05)$. A suplementação mineral apresentou o menor valor entre os suplementos avaliados. Os valores obtidos após suplementação podem ser decorrentes da solubilidade dos suplementos utilizados, principalmente pela utilização da uréia, na composição dos suplementos utilizados.

De acordo com Oliveira et al. (2009), as concentrações de $\mathrm{N}-\mathrm{NH}_{3}$ no rúmen estão associadas à velocidade de introdução e liberação das fontes nitrogenadas no rúmen, bem como à sua assimilação em proteínas microbianas, o que é resultado da sincronia de demais nutrientes que compõem as estruturas celulares dos microrganismos.

Em relação às concentrações de AGCC foi observado efeito $(p<0,05)$ da suplementação, para as concentrações de ácido valérico e o total de AGCC. Ainda foi observado resposta linear decrescente $(p<0,05)$ para as concentrações de valerato (tabela IV). A produção dos ácidos valérico e os isoácidos (isobutírico e isovalérico) é oriunda da fermentação de proteína (Detmann et al., 2001). Concentrações ruminais de isovalérico e isobutírico são indicativos de fermentação de aminoácidos, que em altas concentrações, acumulam AGCC principal fator de redução do pH (Oliveira et al., 2009). Este 
Tabela IV. Medidas de $\mathrm{pH}$, concentrações de $\mathrm{N}-\mathrm{NH}_{3}$, ácidos graxos de cadeia curta de acordo com os suplementos proteicos experimentais (Measures of $\mathrm{pH}$, concentrations of $\mathrm{N}^{-\mathrm{NH}_{3}}$ and short-chain fatty acids according to the experimental protein supplements).

\begin{tabular}{|c|c|c|c|c|c|c|c|c|}
\hline \multirow[t]{2}{*}{ Item } & \multicolumn{4}{|c|}{${ }^{1}$ Suplementos } & \multirow{2}{*}{$\begin{array}{l}\text { CV } \\
(\%)\end{array}$} & \multicolumn{3}{|c|}{${ }^{2}$ Valor de $p$} \\
\hline & 00 & 20 & 40 & 60 & & Suplemento & Linear & Quadrático \\
\hline $\begin{array}{l}\mathrm{pH} \\
\mathrm{mg} / \mathrm{dL}\end{array}$ & 6,92 & 6,72 & 6,67 & 6,62 & 2,05 & 0,020 & 0,346 & 0,867 \\
\hline $\begin{array}{l}\mathrm{N}-\mathrm{NH}_{3} \\
\mathrm{mmol} / \mathrm{L}\end{array}$ & 8,42 & 20,64 & 25,42 & 19,21 & 47,21 & 0,037 & 0,832 & 0,341 \\
\hline Acetato & 81,09 & 84,91 & 96,45 & 81,04 & 20,96 & 0,562 & 0,771 & 0,267 \\
\hline Propionato & 17,05 & 17,28 & 19,25 & 16,38 & 20,68 & 0,786 & 0,737 & 0,316 \\
\hline Isobutirato & 4,02 & 4,30 & 4,24 & 3,77 & 11,89 & 0,774 & 0,173 & 0,511 \\
\hline Butirato & 9,92 & 10,45 & 11,53 & 9,63 & 21,37 & 0,648 & 0,623 & 0,314 \\
\hline Isovalerato & 1,46 & 1,32 & 1,51 & 1,19 & 17,87 & 0,450 & 0,560 & 0,179 \\
\hline Valerato & 2,20 & 2,18 & 2,25 & 1,66 & 12,70 & 0,030 & 0,031 & 0,084 \\
\hline AGCC total & 115,76 & 120,45 & 135,27 & 113,46 & 19,98 & 0,020 & 0,697 & 0,263 \\
\hline $\mathrm{C} 2 / \mathrm{C} 3$ & 4,75 & 4,92 & 5,01 & 4,99 & 4,34 & 0,130 & 0,637 & 0,728 \\
\hline
\end{tabular}

${ }^{1}$ Suplemento 00 (sal mineralizado); Suplemento 20 (suplemento proteico com $20 \%$ de PB); Suplemento 40 (suplemento proteico com $20 \%$ de PB); Suplemento 60 (suplemento proteico com $60 \%$ de PB). ${ }^{2}$ Probabilidade de efeito de dieta, linear e quadrático.

Tabela V. Excreção de derivados de purinas e síntese de proteína microbiana de acordo com os suplementos proteicos experimentais (Excretion of purine derivatives and microbial protein synthesis according to the experimental protein supplements).

\begin{tabular}{|c|c|c|c|c|c|c|c|c|}
\hline \multirow[t]{2}{*}{ Item } & \multicolumn{4}{|c|}{${ }^{1}$ Suplementos } & \multirow{3}{*}{$\begin{array}{l}\text { CV } \\
(\%)\end{array}$} & \multicolumn{3}{|c|}{${ }^{2}$ Valor de $p$} \\
\hline & 00 & 20 & 40 & 60 & & Suplemento & Linear & Quadrático \\
\hline \multicolumn{8}{|l|}{$\mathrm{mmol} / \mathrm{dia}$} & \\
\hline Alantoina & 221,52 & 191,46 & 188,41 & 283,99 & 35,95 & 0,124 & 0,554 & 0,127 \\
\hline Acido úrico & 11,36 & 12,16 & 11,82 & 10,10 & 27,10 & 0,284 & 0,564 & 0,543 \\
\hline Purinas abs. & 230,16 & 193,93 & 190,04 & 222,46 & 41,43 & 0,453 & 0,456 & 0,232 \\
\hline Derivados & 221,52 & 199,77 & 195,97 & 294,53 & 35,22 & 0,768 & 0,786 & 0,865 \\
\hline \multicolumn{9}{|l|}{ g/dia } \\
\hline $\mathrm{N}$ microbiano & 167,33 & 140,99 & 138,16 & 222,46 & 41,43 & 0,789 & 0,453 & 0,345 \\
\hline PB microbiano & 1045 & 881 & 864 & 1390 & 41,43 & 0,789 & 0,453 & 0,345 \\
\hline \multicolumn{9}{|l|}{ gPBmic/kgNDT } \\
\hline Eficiência & 220,07 & 186,45 & 176,14 & 291,33 & 43,55 & 0,554 & 0,209 & 0,672 \\
\hline
\end{tabular}

${ }^{1}$ Suplemento 00 (sal mineralizado); Suplemento 20 (suplemento proteico com $20 \%$ de PB); Suplemento 40 (suplemento proteico com $20 \%$ de PB); Suplemento 60 (suplemento proteico com $60 \%$ de PB). ${ }^{2}$ Probabilidade de efeito de dieta, linear e quadrático.

fato evidencia a ocorrência de alta taxa de desaminação de aminoácidos no rúmen, em que se verifica alta correlação entre os ácidos graxos de cadeia ramificada e o nível de amônia ruminal.

\section{SíNTESE DE PROTEÍNA MICROBIANA}

Não foi obtido efeito $(p>0,05)$ da suplementação proteica sobre a síntese de proteína microbiana e não foi observado $(p>0,05)$ resposta linear ou quadrática em relação às dietas experimentais (tabela $\mathbf{V}$ ). A quantificação da síntese de proteína microbiana em bovinos pelo método da excreção urinária de derivados de purina indica que o fluxo duodenal de ácidos nucléicos é essencialmente de origem microbiana e, após a digestão intestinal dos nucleotídeos de purinas, as bases adenina e guanina são catabolizadas e excretadas proporcionalmente na urina como derivados de purinas, principalmente alantoína, e também ácido úrico (Valadares et al., 1999).

A proteína microbiana pode contribuir com 50,0 a 100,0\% das exigências de proteína metabolizável requerida por bovinos de corte (Goes et al., 2010). Detmann et al. (2005) ressaltaram que fermentações extensas de carboidratos podem ocorrer, mas resultam em baixo crescimento microbiano caso os compostos nitrogenados sejam fornecidos de forma inadequada. Em situações de elevada participação do nitrogênio não-protéico sobre a proteína bruta da dieta basal, com limitação da fração protéica degradada no rúmen de natureza orgânica (aminoácidos e peptídeos), o desempenho animal pode ser comprometido (Detmann et al., 2007). 
Tabela VI. Depuração de ureia e creatinina de acordo com os suplementos proteicos experimentais (Urea and creatinine clearance according to the experimental protein supplements).

\begin{tabular}{|c|c|c|c|c|c|c|c|c|}
\hline \multirow[t]{2}{*}{ Item } & \multicolumn{4}{|c|}{${ }^{1}$ Suplementos } & \multirow{2}{*}{$\begin{array}{l}\text { CV } \\
(\%)\end{array}$} & \multicolumn{3}{|c|}{${ }^{2}$ Valor de $\mathrm{p}$} \\
\hline & 00 & 20 & 40 & 60 & & Suplemento & Linear & Quadrático \\
\hline Urina (L) & 13,63 & 12,10 & 11,44 & 12,09 & 26,82 & 0,567 & 0,674 & 0,439 \\
\hline \multicolumn{9}{|l|}{$m g / d L$} \\
\hline $\begin{array}{l}\text { Creatinina } \\
\text { plasma }\end{array}$ & 18,28 & 16,88 & 19,08 & 19,11 & 7,39 & 0,764 & 0,365 & 0,456 \\
\hline Uréia plasma & 14,99 & 17,32 & 20,67 & 20,39 & 13,29 & 0,145 & 0,349 & 0,235 \\
\hline $\begin{array}{l}\text { Creatinina } \\
\text { urina }\end{array}$ & 34,77 & 55,45 & 41,08 & 91,88 & 52,60 & 0,764 & 0,365 & 0,456 \\
\hline Uréia urina & 17,57 & 28,40 & 37,74 & 42,00 & 30,25 & 0,238 & 0,678 & 0,675 \\
\hline \multicolumn{9}{|c|}{ Excreção (mg/kgPV) } \\
\hline Uréia & 580,30 & 637,51 & 839,23 & 1107,99 & 15,92 & 0,123 & 0,674 & 0,675 \\
\hline Creatinina & 31,27 & 25,52 & 22,81 & 72,86 & 43,29 & 0,675 & 0,453 & 0,672 \\
\hline Uréia-N & 270,42 & 297,66 & 390,01 & 516,32 & 15,92 & 0,236 & 0,678 & 0,345 \\
\hline Creatinina-N & 10,81 & 13,66 & 8,92 & 25,01 & 43,92 & 0,563 & 0,673 & 0,673 \\
\hline
\end{tabular}

${ }^{1}$ Suplemento 00 (sal mineralizado); Suplemento 20 (suplemento proteico com $20 \%$ de PB); Suplemento 40 (suplemento proteico com $20 \%$ de PB); Suplemento 60 (suplemento proteico com $60 \%$ de PB). ${ }^{2}$ Probabilidade de efeito de dieta, linear e quadrático.

Tabela VII. Consumo, excreção e balanço de nitrogênio de acordo com os suplementos proteicos experimentais (Intake, excretion and balance of nitrogen according to the experimental protein supplements).

\begin{tabular}{|c|c|c|c|c|c|c|c|c|}
\hline \multirow[t]{2}{*}{ Item } & \multicolumn{4}{|c|}{${ }^{1}$ Suplementos } & \multirow{2}{*}{$\begin{array}{l}\text { CV } \\
(\%)\end{array}$} & \multicolumn{3}{|c|}{${ }^{2}$ Valor de $\mathrm{p}$} \\
\hline & 00 & 20 & 40 & 60 & & Suplemento & Linear & Quadrático \\
\hline \multicolumn{9}{|c|}{ Consumo (g/dia) } \\
\hline Nitrogênio & 84,65 & 70,59 & 124,83 & 137,08 & 66,59 & 0,547 & 0,234 & 0,839 \\
\hline \multicolumn{9}{|c|}{ Excreção de nitrogênio (g/dia) } \\
\hline Fezes & 19,09 & 21,65 & 26,52 & 32,14 & 55,83 & 0,364 & 0,657 & 0,645 \\
\hline Urina & 22,89 & 14,99 & 15,35 & 19,65 & 53,66 & 0,786 & 0,876 & 0,378 \\
\hline \multicolumn{9}{|c|}{ Balanço de nitrogênio (g/dia) } \\
\hline Retido & 42,67 & 37,03 & 82,97 & 85,29 & 98,67 & 0,765 & 0,219 & 0,258 \\
\hline Absorvido & 65,56 & 52,02 & 98,31 & 104,94 & 67,56 & 0,275 & 0,493 & 0,693 \\
\hline
\end{tabular}

${ }^{1}$ Suplemento 00 (sal mineralizado); Suplemento 20 (suplemento proteico com $20 \%$ de PB); Suplemento 40 (suplemento proteico com $20 \%$ de PB); Suplemento 60 (suplemento proteico com $60 \%$ de PB). ${ }^{2}$ Probabilidade de efeito de dieta, linear e quadrático.

\section{BALANÇO DE COMPOSTOS NITROGENADOS}

Não foi obtido efeito $(\mathrm{p}>0,05)$ da suplementação proteica sobre o balanço de compostos nitrogenados e não foi observada $(p>0,05)$ resposta linear ou quadrática em relação às dietas experimentais (tabela VI).

A uréia plasmática é eliminada pelos rins, por filtração glomerular e reabsorção tubular por processo passivo, secundário à reabsorção de fluidos (Owens and Zinn, 1993). Assim, a quantidade de uréia excretada é influenciada por estas funções, além de ser, alterada principalmente por sua concentração plasmática, sob várias condições dietéticas. A excreção urinária de creatinina é mensurada a partir da coleta total de urina e parece não ser afetada pela dieta. Rennó et al. (2000) concluíram que a excreção diária de creatinina não foi influenciada pela inclusão de concentrado na dieta, apresentando média de $27,36 \mathrm{mg} / \mathrm{kg}$ PV, para bovinos de corte. Orskov and Macleod (1982) observaram relativa constância nas excreções basais de compostos nitrogenados e de creatinina e constataram que, além de a excreção de creatinina ser constante, é também proporcional ao peso corporal e pouco afetada pelo teor de compostos nitrogenados da dieta.

\section{BALANÇO DE NITROGÊNIO}

Não foi obtido efeito $(p>0,05)$ da suplementação proteica sobre o balanço de nitrogênio e não foi observada $(p>0,05)$ resposta linear ou quadrática em relação às dietas experimentais (tabela VII).

Mesmo sem efeito estatístico houve, aumento linear no nitrogênio retido e absorvido principalmente para os suplementos 40 e 60 . O balanço de nitrogênio (BN) positivo em todos os níveis de suplementos das tratametos experimentais, indicando adequado balanceamento de proteína e energia nas dietas e ausência de mobilização de reservas corporais, mesmo quando a ração continha maior proporção de volumoso. 
Tabela VIII. Comportamento ingestivo de suplemento proteico de acordo com os suplementos proteicos experimentais (Feeding behavior of proteic supplement according to the experimental protein supplements).

\begin{tabular}{|c|c|c|c|c|}
\hline \multirow{2}{*}{ Suplemento } & \multirow[t]{2}{*}{ Estimativa } & \multicolumn{2}{|c|}{$\begin{array}{l}\text { Intervalo assintótico de } 95 \% \\
\text { de confiança da estimativa }\end{array}$} & \multirow[t]{3}{*}{$\begin{array}{l}\text { Erro padrão } \\
\text { assintótico }\end{array}$} \\
\hline & & $\begin{array}{l}\text { Limite } \\
\text { inferior }\end{array}$ & $\begin{array}{l}\text { Limite } \\
\text { superior }\end{array}$ & \\
\hline & \multicolumn{3}{|l|}{ Parâmetro a } & \\
\hline 20 & 1.105 & 939,4 & 1.272 & 82,3 \\
\hline 40 & 821,0 & 638,4 & 1.004 & 90,4 \\
\hline \multirow[t]{2}{*}{60} & 858,4 & 579,6 & 1.137 & 138 \\
\hline & \multicolumn{3}{|l|}{ Parâmetro $k$} & \\
\hline 20 & 0,0051 & 0,0032 & 0,0070 & 0,0010 \\
\hline 40 & 0,0059 & 0,0024 & 0,0095 & 0,0018 \\
\hline 60 & 0,0045 & 0,0009 & 0,0081 & 0,0018 \\
\hline
\end{tabular}

Suplemento 20 (suplemento proteico com $20 \%$ de PB); Suplemento 40 (suplemento proteico com $20 \%$ de PB); Suplemento 60 (suplemento proteico com $60 \%$ de PB). Parâmetro $a=$ intervalos de consumo; Parâmetro $k=$ velocidade de ingestão.

\section{COMPORTAMENTO INGESTIVO DE SUPLEMENTO}

A avaliação do comportamento ingestivo mostrou não haver diferença entre o consumo dos suplementos ocorrendo sobreposição (tabela VII). Durante o experimento, o consumo diário dos suplementos variou de 579 a $1.272 \mathrm{~g} /$ dia. O parâmetro $a$ representa a estimativa de consumo dia a dia dos diferentes suplementos com confiabilidade de $95 \%$ de certeza.

Apresentando os suplementos 40 e 60 similaridades nos valores com representatividade nas linhas próximas nos valores assintóticos. Porém o limite superior do suplemento 60 no parâmetro $a$ obteve valor semelhante ao tratamento de maior ingestão, contrariando dados relatados por Paulino et al. (1983), citando que aumento do teor de uréia diminuiu o consumo $(\mathrm{kg}$ MS/animal/dia). Estando os valores dos limites inferiores do parâmetro $a$ condizente a tal afirmação. Os valores estimados pelo modelo aqui observado estão de acordo com o consumo de suplemento in vivo apresentado na (tabela III). Por outro lado, os altos valores de erro padrão assintótico para esta estimativa evidenciaram a variabilidade de consumo observada.

Os intervalos de confiança estimados para o parâmetro velocidade de ingestão (parâmetro $k$ ) não foram alterados, indicando a não existência de diferenças para a velocidade de ingestão de suplemento. No entanto tendo interação inversa da velocidade e consumo para tratamento de menor valor de consumo apresentando velocidade de ingestão intermediaria o suplemento 20.

O consumo de suplemento 60 apresentou a menor estimativa de velocidade relativa a tal observação. Vários fatores podem ter influenciado este parâmetro como o pH ruminal, a quantidade total de concentrado ingerido e a porcentagem de uréia.

\section{CONCLUSÃO}

Os níveis de suplementação proteica não influenciaram o consumo de matéria seca, síntese de proteína microbiana e balanço de compostos nitrogenados, porem influenciaram as concentrações de ácidos graxos de cadeia ramificada e a velocidade de consumo de suplemento proteico.

\section{AGRADECIMENTOS}

$$
\text { FUNDECT - MS e Cnpq. }
$$

\section{BIBLIOGRAFIA}

AOAC. 2000. Official Methods of Analysis. 17th ed. AOAC Int. Gaithersburg. MD.

Brody, S. 1945. Bioenergetics and growth. Reinhold Publishing. New York. 1023 pp.

Campos, F.P.; Nussio, C.M.B. e Nussio, L.G. 2004. Métodos de análise de alimentos. FEALQ. 135 pp.

Capelle, E.R.; Valadares Filho, S.C. e Silva, J.F.C. 2001. Estimativas do valor energético a partir de características químicas e bromatológicas dos alimentos. Rev Bras Zootecn, 30: 1837-1856.

Casali, A.O.; Detmann, E. e Valadares Filho, S.C. 2008. Influência do tempo de incubação e do tamanho de partículas sobre os teores de compostos indigestíveis em alimentos e fezes bovinas obtidos por procedimentos in situ. Rev Bras Zootecn, 37: 335-342.

Chen, X.B. e Gomes, M.J. 1992. Estimation of microbial protein supply to sheep and cattle based on urinary excretion of purine derivatives - an overview of technical details. Rowett Research Institute. Bucksburnd. $21 \mathrm{pp}$.

Detmann, E.; Cecon, P.R.; Paulino, M.P.; Valadares Filho, S.C.; Henriques, L.T. e Detmann, K.S.C. 2007. Variáveis ruminais avaliadas por meio de funções matemáticas contínuas. Pesq Agropec Bras, 42: 456-467.

Detmann, E.; Paulino, M.F. e Cecon, P.R. 2005. Níveis de proteína em suplementos para terminação de bovinos em pastejo durante o período de transição seca/águas: Consumo voluntário e trânsito de partículas. Rev Bras Zootecn, 34: 1371-1379.

Detmann, E.; Paulino, M.F.; Zervoudakis, J.T.; Valadares Filho, S.C.; Euclydes, R.F.; Lana, R.P. e Queiroz, D.S. 2001. Cromo e indicadores internos na estimação do consumo de novilhos mestiços, suplementados, a pasto. Rev Bras Zootecn, 30: 1600-1609.

Erwin, E.S.; Marco, G.J. e Emery, E.M. 1961. Volatile fatty acid analyses of blood and rumen fluid by gas chromatography. J Dairy Sci, 44: 1768-1777.

Euclides, V.P.B.;Macedo, M.C.M.;Zimmer, A.H.;Medeiros, R.N. eOliveira, M.P. 2007. Características do pasto de capim-tanzânia adubado com nitrogênio no final do verão. Pesq Agropec Bras, 42: $1189-1198$.

Ferreira, G.D.G.; Viana, R.B.; Cardoso, E.C.; Araújo, C.V.; Melo, W.O.; Monteiro, B.M. eSouza, D.C. 2012 . Disponibilidade quali-quantitativa da Brachiaria brizantha cv. Marandu pastejada por búfalos no Pará. Rev Acad Ciênc Agrár Ambient, 10: 45-50.

Fujihara, T.; Orskov, E.R.; Reeds, P.J. e Kyle, D.J. 1987. The effect of protein infusion on urinary excretion of purine derivatives in ruminants nourished by intragastric nutrition. J Agricul Sci, 10: 7-12.

Goes, R.H.T.B.; Mancio, A.B.; Lana, R.P.; Cecon, P.R.; Alves, D.D.; Freitas, T.B. e Brabes, K.C.S. 2010. Suplementação protéica e energética para novilhos em recria, durante o período da seca. Rev Bras Saúde Prod Anim, 11: 1081-1094.

Kaps, M. e Lamberson, W.R. 2004. Biostatistics for animal science. Cambridge. CABI Publishing. USA. 445 pp.

Lima, H.L.; Goes, R.H.T.B.; Cerilo, S.L.M.; Oliveira, E.R.; Brabes, K.C.S. e Teodoro, A.L. 2012. Nutritional value of Marandu grass, under grazing by three sampling methods. Acta Sci Anim Sci, 34: 379-384. Lima, J.B.M.P.; Rodríguez, N.M.; Martha Júnior, G.B.; Guimarães Júnior, R.; Vilela, L.; Graça, D.S. e Saliba, E.O.S. 2012. Suplementação de 
novilhos Nelore sob pastejo, no período de transição águas-seca. Arq Bra Med Vet Zootec, 64: 943-952.

McMeniman, N.P. 1997. Methods of estimating intake of grazing animals. In: Simpósio Sobre Tópicos Especiais em Zootecnia, 34, 1997. Anais... SBZ. Juiz de Fora. pp. 131-168.

Oliveira, L.O.F.; Saliba, E.O.S.S; Borges, I; Gonçalves, L.C.; Fialho, M.P.F e Miranda. P.A.B. 2009. Parâmetros ruminais síntese de proteína metabolizável em bovinos de corte sob suplementação com proteinados contendo diversos níveis de proteína bruta. Rev Bras Zootecn, 38: 2506-2515.

Ørskov, E.R. e Macleod, N.A. 1982. The determination of the minimal nitrogen excretion in steers and dairy cows and physiological and practical implications. Brit J Nut, 47: 625-636.

Owens, F.N. e Zinn, R. 1993. Protein metabolism of ruminant animals. In: Church D.C. (Ed). The ruminant animal: Digestive physiology and nutrition. Waveland Press, Inc. Englewood Cliffs, NJ. pp. 227-249.

Paulino, M.F.; Silva, H.M. e Ruas, J.R.M. 1983. Efeitos de diferentes níveis de uréia sobre o desenvolvimento de novilhas zebu. Arq Bras Med Vet Zootec, 35: 231-245.

Poppi, D.P. e McLennan, S.R. 1995. Protein and energy utilization by ruminants at pasture. J Anim Sci, 73: 278-290.
Rennó, L.N.; Valadares, R.F. e Valadares Filho, S.C. 2000. Concentração plasmática de uréia e excreções de uréia e creatinina em novilhos. Rev Bras Zootecn, 29: 1235-1243.

Sales, M.F.L.; Paulino, M.F. e Valadares Filho, S.C. 2008. Níveis de ureia em suplementos múltiplos para terminação de novilhos em pastagem de capim-braquiária durante o período de transição águas-seca. Rev Bras Zootecn, 37: 1704-1712.

Silva, F.F.; Sá, J.F.; Schio, A.R.; Itavo. L.C.V.; Silva, R.R. e Mateus, R.G. 2009. Suplementação a pasto: disponibilidade e qualidadexníveis de suplementaçãox desempenho. Rev Bras Zootecn, 38: 371-389.

Valadares, R.F.D.; Broderick, G.A. e Valadares Filho, S.C. 1999. Effect of replacing alfalfa silage with high moisture corn on ruminal protein synthesis estimated from excretion of total purine derivatives. J Dairy Sci, 82: 2686-2696.

Van Soest, P.J.; Robertson, J.B. e Lewis, B.A.1991. Methods for dietary fiber, neutral detergent fiber, and nonstarch polysaccharides in relation to animal nutrition. J Dairy Sci, 74: 3583-3597.

Verbic, J.; Chen, X.B.; Macleod, N.A. e Ørskov, E.R. 1990. Excretion of purine derivatives by ruminants. Effect of microbial nucleic acid infusion on purine derivative excretion by steers. J Agricul Sci, 114: 243-248. 
